\title{
APLIKASI SMART TRY OUT SYSTEM BERBASIS KOMPUTER UNTUK PESIAPAN UJIAN NASIONAL BERBASIS KOMPUTER SISWA SMK
}

\author{
Dwi Setia Mujiono', Jatmiko Indriyanto ${ }^{2}$ \\ Email: dwichoshy@gmail.com \\ Program Studi Teknik Komputer Politeknik Harapan Bersama Tegal
}

\begin{abstract}
Abstrak
Berbagai masalah yang di alami peserta didik dengan adanya ujian Nasional berbasis komputer adanya kurang adanya alat untuk melakukan tryout ujian nasional. penelitian yang dilakukan tujuan penelitian ini untuk mengetahui cara mengembangkan Smart Try Out System sebagai perangkat tes berbasis komputer mata pelajaran ujian nasional dan mengetahui apakah perangkat tes yang dikembangkan memenuhi kualifikasi tes yang dapat digunakan mengukur kemampuan peserta didik. Dengan metode penelitian yang digunakan dalam penelitian adalah metode Recearch And Development (R \& D). Hasil penelitian menunjukkan bahwa tanggapan dari guru ujian nasional berupa persentase tingkat pencapaian mencapai persentase $92 \%$ berada pada kualifikasi baik. Tanggapan menurut ahli media mencapai persentase $80 \%$ berada pada kualifikasi baik untuk penilaian pemprograman dan $76 \%$ berada pada kualifikasi baik untuk penilaian tampilan. Tanggapan pada hasil ujicoba satu-satu yang dilakukan pada 10 peserta didik mencapai persentase $82,72 \%$ berada pada kualifikasi baik dan tanggapan pada hasil ujicoba lapangan yang dilakukan pada 50 orang siswa mencapai persentase $87,36 \%$ berada pada kualifikasi baik. Berdasarkan penelitian ini telah berhasil dikembangkan sebuah perangkat tes yang diberi nama Smart Try Out System yang mendapat respon rata-rata dengan kualifikasi baik.
\end{abstract}

Kata kunci: Komputer, Smart Try Out System, UNBK

\section{Pendahuluan}

Ujian merupakan salah satu cara mengevaluasi hasil belajar. Dalam dunia pendidikan ujian digunakan untuk mengukur taraf pencapaian suatu tujuan pengajaran ke pada peserta didik, sehingga peserta didik dapat mengetahui sejauh mana kemampuan peserta didik terhadap pelajaran yang di ikutinya. Bila ternyata hasilnya maka harus ditingkatkan kualitas maupun kuantitasnya (Clara, 2006).

Ujian Nasional Berbasis Komputer (UNBK) disebut juga Computer Based Test (CBT) adalah sistem pelaksanaan ujian nasional dengan menggunakan komputer sebagai media ujiannya. Dalam pelaksanaannya, UNBK berbeda dengan sistem ujian nasional berbasis kertas atau Paper Based Test (PBT) yang selama ini sudah berjalan.

Pengukuran Berbasis Komputer atau juga dikenal sebagai Tes Berbasis Komputer (Computer-Based Testing) adalah metode test dimana pengaturan setiap respon jawaban disimpan, dinilai, atau keduanya secara elektronik. Sesuai dengan namanya, pengukuran berbasis komputer menggunakan komputer atau perangkat elektronik yang setara seperti telepon genggam, PDA dan lain-lain untuk mengukur hasil belajar siswa. Pengukuran berbasis komputer memungkinkan guru atau instruktur untuk mengatur, menjadwalkan, melaksanakan ujian, mengirim data serta melaporkannya.
Berdasarkan uraian di atas akan dibuat sebuah aplikasi sistem ujian try out UNBK berbasis komputer yang merupakan suatu perangkat lunak untuk pelaksanaan ujian secara try out UNBK di lingkungan SMK. Sistem ujian try out UNBK berbasis komputer ini dibuat agar dapat memberikan suatu gambaran mengenai bagaimana suatu sistem berjalan dan bagaimana sistem tersebut dapat menjadi acuan dalam pengembangan sistem yang lebih lanjut. Algoritma perancangan program yang telah dibuat pada aplikasi sistem ujian try out UNBK ini, selanjutnya dianalisa untuk mengetahui keberhasilan aplikasi ini.

\section{Metode Penelitian}

Metode Recearch And Development (R \& D) yang diungkapkan bolg dan Gall (1989: 784) terbagi atas beberapa tahapan diantaranya: Penelitian dan pengumpulan data (Recearch And Information collecting), Perencanaan (planning), Pengembangan draf produk (develop prelimenary form of product), Uji coba lapangan awal (prelimenary field testing), Merevisi hasil uji coba (main product revision), Uji coba lapangan (mail field testing), Penyempurnaan produk uji lapangan (operational product revision), $\mathrm{Uji}$ pelaksanaan lapangan (operational field testing),Penyempurnaan akhir produk (final product revision), dan Desiminasi dan implementasi (dissemination and implementation) 


\section{Hasil dan Pembahasan}

Hasil adalah temuan penelitian yang disajikan tanpa pendapat. Analisa menguraikan secara tepat dan argumentatif hasil penelitian dengan teori dan temuan terdahulu yang relevan. Jika ada tabel atau gambar dalam hasil dan pembahasan, diketik dengan spasi 1 ukuran front 10 pt dan diberi nomor urut sesuai dengan penampilan dalam teks. Jumlah maksimal tabel atau gambar dengan judul singkat adalah 6 gambar atau tabel. ${ }^{[2] .}$

\section{Alur Sistem}

Sistem Smart Try Out System berbasis web dikembangkan atas dasar fungsi operasi dari user guru dan peserta didik yang harus dilakukan dalam menempuh ujian konvensional. guru dan peserta didik adalah pengguna sistem yang melakukan proses ujian, didalam sistem ini guru sebagai penyedia bahan ujian sedangkan peserta didik adalah peserta ujian. Sementara itu administrator adalah pengguna dari sistem yang menyediakan layanan atau sebagai pengelola sistem agar user guru dan peserta didik dapat melaksanakan proses ujian didalam sistem tanpa masalah.

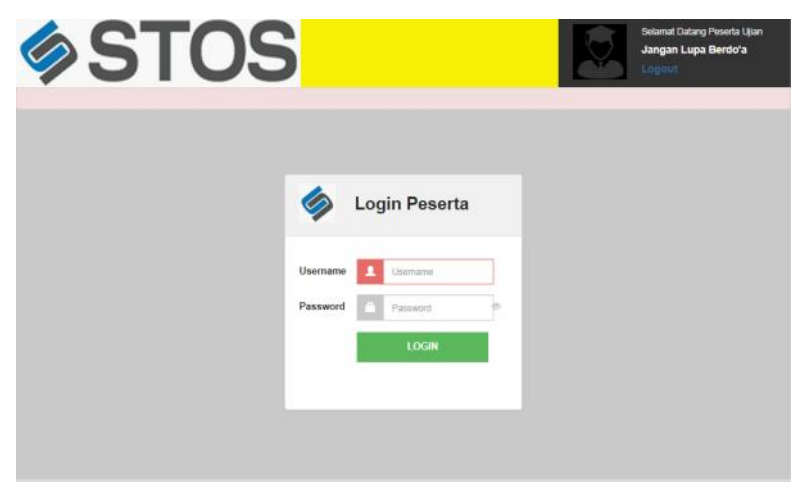

Gambar 1. Tampilan Login Sistem

Berdasarkan kebutuhan dari user terhadap sistem berikut ini dijelaskan fungsi masingmasing entitas user dalam sistem:

1. Entitas guru: user guru merupakan entitas external yang menggunakan sistem dalam hal memberikan bahan ujian kepada user peserta didik.

Fungsi: menguji matakuliah, membuat soal, mengatur ujian

2. Entitas Peserta didik: user peserta didik merupakan entitas external dari sistem yang melakukan ujian secara online berdasarkan bahan yang diberikan oleh user guru.

Fungsi: melaksanakan ujian, menerima nilai
3. Entitas Administrator: administrator adalah pemelihara dan pengelola sistem yang menyediakan berbagai kebutuhan dari user guru dan Peserta didik terhadap sistem.

Fungsi: mengelola basis data sistem

Dalam Gambar berikut ditampilkan alur proses sistem yang terjadi didalam operasional sistem berdasarkan fungsi kebutuhan masing-masing user.

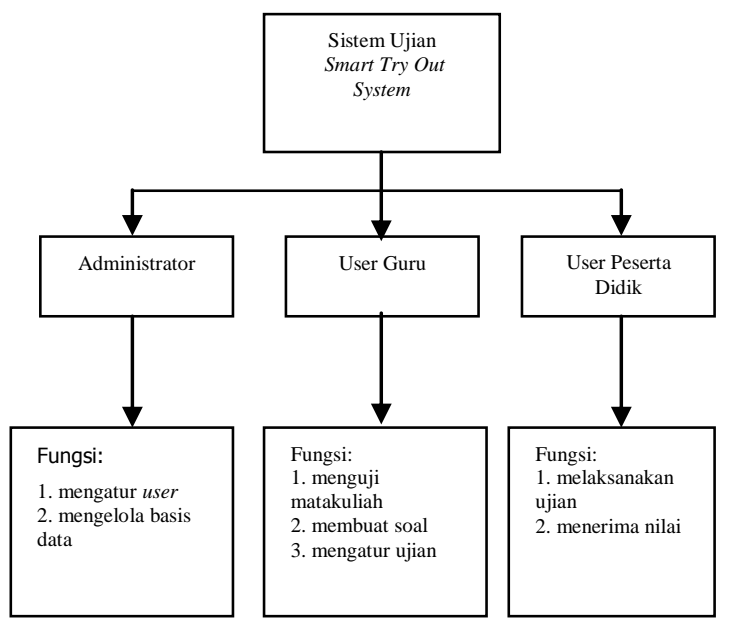

Gambar 2. Kerangka Entitas User

Pengembangan program aplikasi ujian nasional Online Berbasis Smart Try Out System memnunjukan antusiasme siswa dalam mengerjakan. hal ini dikarenakan program ini akan mengenalkan mereka tentang ujian nasional yang akan dilakukan nantinya. berikut adalah beberapa tampilan keseluruhan program aplikasi ujian nasional Online Berbasis Smart Try Out System yang sudah selesai di buat.

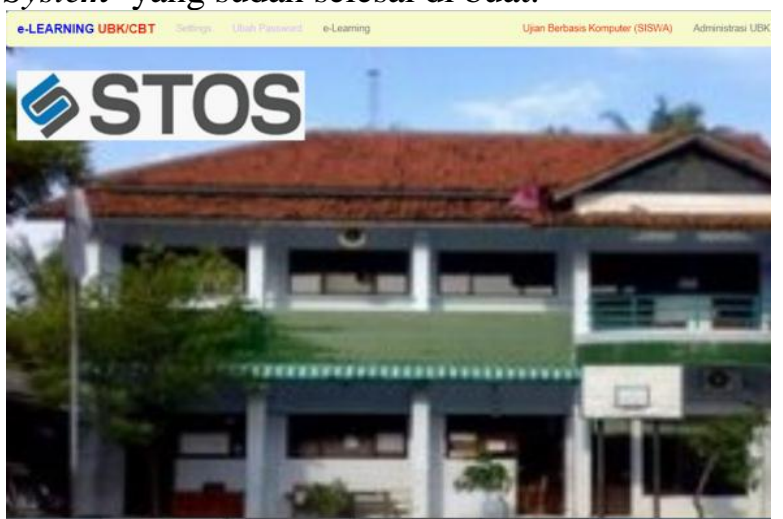

Gambar 3. Tampilan Awal Sistem

Tampilan ini akan muncul ketika kita akan masuk ke aplikasi. di tampilan ini akan ada pilihan berbagai menu antara lain ujian masuk UNBK (untuk siswa) dan menu administrator UNBK. 


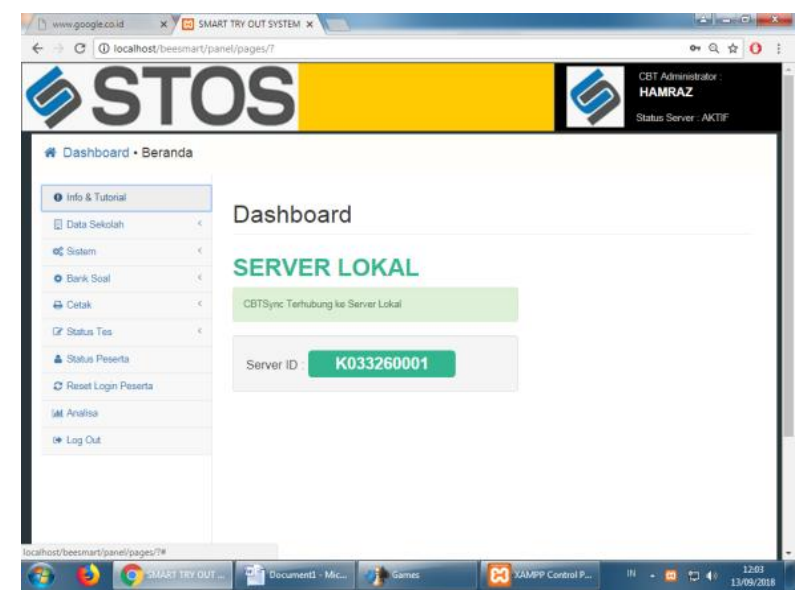

Gambar 4. Tampilan Halaman Dashboard Sistem

Dimenu ini terdiri dari berbagai sub menu yaitu sistem server, data sekolah, adminstrai bank soal, cetak status ujian, status peserta, reset login peserta, analisis dan log out. berikut adalah menumenu setelah kita masuk ke masing-masing menu tersebut.

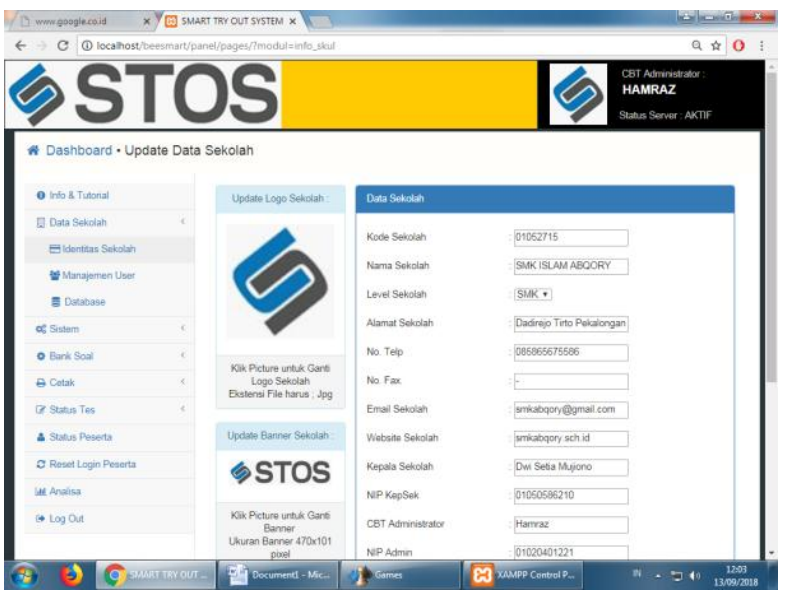

Gambar 5. Menu Update Data Sekolah

\section{Kesimpulan}

Aplikasi Smart Try Out System yaitu suatu perangkat lunak komputer yang dikembangkan untuk membantu peserta didik melakukan latihan ujian nasional. Dengan kata lain Smart Try Out System merupakan perangkat tes berbasis komputer yang dikembangkan oleh penulis sendiri. Tujuan utama dari pengembangan Smart Try Out System adalah melatih peserta didik agar lebih siap dalam menghadapi ujian tertulis yang sebenar-nya. Secara khusus Smart Try Out System diharapkan dapat membantu peserta didik mengerjakan soal ujian nasional dengan mudah. Dalam Smart Try Out System, peserta didik diberikan soal untuk dikerjakan dan soal itu telah di acak oleh sistem komputer.

\section{Daftar Pustaka}

[1]. Aditya, A.L. jago PHP \& MySQL, dunia komputer, Jakarta, 2011.

[2]. Anhar, Panduan Menguasai PHP dan MySQL, Jakarta, 2010

[3]. Borg, Walter R., Gall M. D \& Gall, Joyce P. 2003. Educational Research: an Introduction 7 th Ed. New York: Pearson Education .Inc

[4]. Clara.2006.Pengertian Ujian. diambil dari http://repository.upi.edu/1343/2/s d5451 0706537 chapter1.pdf

[5]. Kurniawan, R, PHP \& MySQL untuk Orang Awam, Maxikom, Palembang, 2010.

[6]. Martin, Romain, "New Possibilities and Challenges Forassessment through the Use of Technology", dalam Friedrich Scheuermann \& Angela Guimarães Pereira (Eds.), Towards a Research Agenda on Computer-Based Assessment. http://www.jrc.ec. europa.eu/Diakses tanggal 15 Januari 2017.

[7]. Rosa D, dkk, Pemrograman Basis Data Berbasis Web Menggunakan PHP dan MySQL, Bangkalan, 2010

[8]. Sucipto, Konsep dan Teknik Pengembangan Sistem berbasis Teknologi Informasi, Banten, 2010

[9].Virgi, Cepat Mahir Pemrograman Web dengan PHP dan MySQL, Jakarta, 201 